\title{
Enzyme electrodes stabilized by monolayer-modified nanoporous Au for biofuel cells
}

\author{
Masataka Hakamada • Masaki Takahashi • \\ Mamoru Mabuchi
}

Published online: 6 December 2011

(C) The Author(s) 2011. This article is published with open access at Springerlink.com

\begin{abstract}
Open-cell nanoporous $\mathrm{Au}(\mathrm{np}-\mathrm{Au})$ electrodes with pore size of approximately $40 \mathrm{~nm}$ were fabricated by dealloying of $\mathrm{Au}-\mathrm{Ag}$, and surfaces of the electrodes were modified with a self-assembled monolayer (SAM) of 4aminothiophenol to enhance the electrocatalytic activities of immobilized laccase and glucose oxidase. Enzymeimmobilized SAM-modified np-Au working electrodes exhibited additional reduction-oxidation peak pairs in cyclic voltammograms in buffer solution $(\mathrm{pH}=5.0)$. Thus, the SAM on the np-Au facilitated electron transfer between the electrode and reactants. First-principles calculations of perfect and defective $\mathrm{Au}$ (111) surfaces indicated that the atomic defects at nanoligament surface of np-Au are critically responsible for the electron transfer enhancement. For the utilization of these results, a glucose $/ \mathrm{O}_{2}$ biofuel cell composed of these enzymeimmobilized SAM-modified np-Au electrodes was preliminarily fabricated, and it exhibited a maximum power density of $52 \mu \mathrm{W} / \mathrm{cm}^{2}$ at $20^{\circ} \mathrm{C}$. Further optimization of nanoporous structures and kinds of SAM will improve the performance of biofuel cells.
\end{abstract}

Keywords Nanoporous gold - Laccase - Glucose oxidase . Biofuel cell $\cdot$ Self-assembled monolayer (SAM)

M. Hakamada $(\square) \cdot$ M. Takahashi $\cdot$ M. Mabuchi

Department of Energy Science and Technology,

Graduate School of Energy Science, Kyoto University,

Yoshida Honmachi, Sakyo,

Kyoto 606-8501, Japan

e-mail: hakamada.masataka.3x@kyoto-u.ac.jp

\section{Introduction}

Biofuel cells convert chemical energy into current-using enzymes as biocatalysts and are promising devices for harvesting bioenergy [1-4]. The essential feature of enzymatic biofuel cells is that power can be produced from a fuel (i.e., glucose) present in the human body $[5,6]$. The main advantage of such fuel cells is their ability to operate under mild conditions at temperatures of $20-40^{\circ} \mathrm{C}$ and at approximately neutral $\mathrm{pH}$ values $[7,8]$.

For implantable and miniature biofuel cells, materials and microstructures of the electrode surfaces are important factors [9-11]. The three-dimensional (3-D) structures and high surface areas of porous materials are attractive in preparing cells to improve power output. Materials with high surface areas such as carbon felt and porous carbon are commonly used as electrodes; however, it remains difficult to control the pore size distribution and, therefore, the real surface area of these materials $[12,13]$. Nanoporous metals with 3-D networks of nanoligaments and nanopores have received much recent interest as supporting matrixes for the loading of biomolecules [14-16]. Monolithic nanoporous metals can be easily prepared by dealloying and have large specific surface areas. Their pore size can be controlled across a wide range from a few nanometers to several micrometers by thermal and/or acid treatments. With these characteristics in mind, nanoporous metals are candidates for the immobilization of enzymes. Their 3-D rigid nanoporous structure increases the number of active sites, which leads to high-density loading and effective spatial dispersion of the enzyme [16-19].

In this study, the electrochemical properties of laccase and glucose oxidase (GOx) immobilized within nanoporous $\mathrm{Au}(\mathrm{np}-\mathrm{Au})$ have been elucidated. The pore size of $\mathrm{np}-\mathrm{Au}$ was adjusted to approximately $40 \mathrm{~nm}$ to ensure high enzyme 
stability [14], and the effect of a self-assembled monolayer (SAM) of 4-aminothiophenol (4-ATP) which enhances the electron transfer [20] was examined. The enhanced electrochemical properties of enzyme-immobilized np-Au with the SAM were due to the strong covalent or electrostatic bonding between SAM amino groups and enzyme lateral amino acids, which facilitated electron transfer.

\section{Experimental}

Preparation of nanoporous and smooth $\mathrm{Au}$

Commercially available $\mathrm{Au}$ ( $>99.9$ mass\%) and $\mathrm{Ag}$ (>99.9 mass\%) ingots were arc-melted together under an $\mathrm{Ar}$ atmosphere to give the precursor $\mathrm{Au}_{0.35} \mathrm{Ag}_{0.65}$ alloy ingot. After homogenization at $1,173 \mathrm{~K}$ for $24 \mathrm{~h}$ under an $\mathrm{Ar}$ atmosphere and cold rolling, nanoporous $\mathrm{Au}$ was synthesized by dealloying at room temperature in 70 mass $\% \mathrm{HNO}_{3}$ for 8 days. Figure 1 shows a scanning electron microscopy (SEM) image of the np-Au in which the average pore size was $40 \mathrm{~nm}$. For reference, a smooth Au surface (without the nanoporous structure) was prepared by grinding rolled $\mathrm{Au}$ plate with 1,200 grit $\mathrm{SiC}$ sandpaper, sonication in ethanol and distilled water for $5 \mathrm{~min}$, immersion in $70 \mathrm{mass} \% \mathrm{HNO}_{3}$ for $3 \mathrm{~min}$, and finally washing with distilled water.

SAM modification and enzyme immobilization

The 4-ATP monolayer was self-assembled on various np-Au samples as well as the smooth Au surface by immersion in a $20 \mathrm{mM}$ ethanolic solution of 4-ATP for $65 \mathrm{~h}$ at room temperature in ambient air. Following immersion, samples were thoroughly rinsed with ethanol and distilled water.

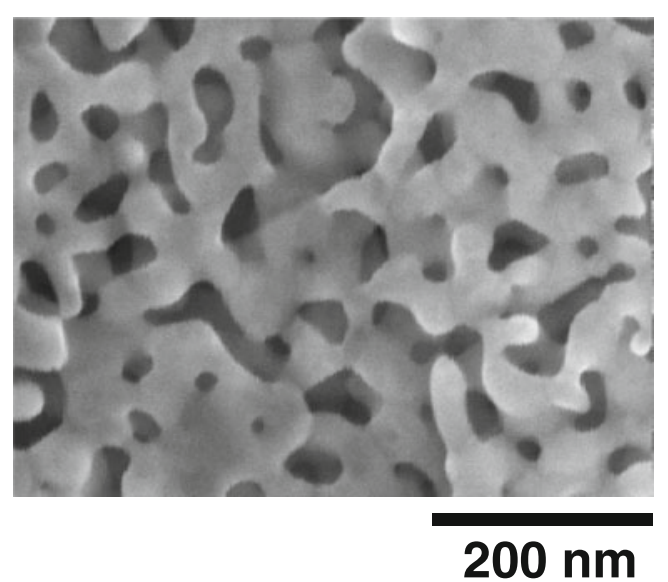

Fig. 1 Scanning electron microscopic image of nanoporous Au with average pore size of $40 \mathrm{~nm}$
Samples (both with and without SAM-modification) were kept quiescently in $2 \mathrm{~mL}$ of $7 \mathrm{mg} / \mathrm{mL}$ laccase (Trametes versicolor from Sigma Aldrich Corp. with an activity of 21 $\mathrm{U} / \mathrm{mg}$ ) or GOx (Aspergillus niger from Nacalai Tesque, Inc. with an activity of $273 \mathrm{U} / \mathrm{mg}$ ) solutions (diluted with $0.1 \mathrm{M}$ citrate $-0.2 \mathrm{M}$ phosphate buffer solution, $\mathrm{pH}=5.0$ ) at $4^{\circ} \mathrm{C}$ for $24 \mathrm{~h}$. Samples were then rinsed five times with $10 \mathrm{~mL}$ of the buffer solution to remove any weakly adsorbed enzyme on the outer surface. Assay by the Bradford method revealed that approximately 25 and $23 \mathrm{mg} / \mathrm{g}_{\mathrm{Au}}$ of laccase were immobilized on the nanoporous $\mathrm{Au}$ samples with and without SAM-modification, respectively.

\section{Electrochemical measurements}

Cyclic voltammetry (CV) was carried out using a potentiostat (HZ-5000 by Hokuto Denko Corp.) at room temperature to elucidate the electrochemical properties and stability of the enzyme-immobilized samples. A three-electrode electrochemical cell with $\mathrm{Pt}$ wire as a counter electrode, the enzyme-immobilized np-Au electrode as a working electrode, and saturated calomel electrode (SCE) as a reference electrode was used. Potentials were documented vs standard hydrogen electrode (SHE) unless otherwise stated. For the laccase-immobilized electrode, the electrolyte of $0.1 \mathrm{M}$ citrate- $0.2 \mathrm{M}$ phosphate buffer solution was air-saturated with dry air bubbling for $1 \mathrm{~h}$. CV was conducted at $100 \mathrm{mV} / \mathrm{s}$ from -0.15 to $0.7 \mathrm{~V}$. For the GOx-immobilized electrode, the electrolyte of $0.1 \mathrm{M}$ citrate $-0.2 \mathrm{M}$ phosphate buffer solution containing $100 \mathrm{mM}$ glucose was air-saturated, and CV was conducted at $100 \mathrm{mV} / \mathrm{s}$ from -0.05 to $0.85 \mathrm{~V}$. In all electrochemical measurements, the apparent exposed area of the working electrode was $9 \mathrm{~mm}^{2}$.

\section{First-principles calculations}

Geometry optimization calculations were performed using the Cambridge Serial Total Energy Package (CASTEP) [21], in which density functional theory $[22,23]$ was used with a plane wave basis set to calculate the electronic properties of solids from first principles. The exchangecorrelation interactions were treated using the spinpolarized version of the generalized gradient approximation within the scheme due to Perdew-Burke-Ernzerhof [24]. Ultra-soft pseudo-potentials [25] represented in reciprocal space were used for all elements in the calculations. The Kohn-Sham wave functions of valence electrons were expanded to the plane wave basis set within a specified cutoff energy $(=340 \mathrm{eV})$. The Brillouin zone was sampled using a Monkhorst-Pack $3 \times 3 \times 1$ k-point mesh in the defective surface models and Gaussian smearing with a width of $0.1 \mathrm{eV}$. 
Calculations were performed using face-centered-cubic (111) surface slab models for the $3 \times 3$ supercells of the $(1 \times 1)$ unit cell in three different surface models to aid comparison with previous reports [26, 27]. The honeycomb and adatom models were generated to simulate the defective surface of $\mathrm{np}-\mathrm{Au}$ by the structural relaxation calculation after removal of atoms from the (111) perfect surface model. All models contained five atomic layers where the two bottom layers were constrained while the rest were allowed to relax. The repeated slabs were separated from each other by a vacuum space of $10 \AA$.

\section{Results and discussion}

Enzyme electrodes

Figure 2 shows $\mathrm{CV}$ curves for the laccase-immobilized $\mathrm{np}-\mathrm{Au}$ electrodes. As shown in Fig. 2a, the laccaseimmobilized np-Au electrode without SAM exhibited one reversible broad peak pair with a midpoint potential of $0.13 \mathrm{~V}$, similar to a previous study [14]. Figure 2a also shows no apparent degradation in the laccase-immobilized np-Au electrode without SAM after 100 cycles of measurement. In contrast, laccase-immobilized np-Au with SAM showed two sets of reduction-oxidation (redox) peaks in the CV curves (Fig. 2b). The first and second peak pairs had midpoint potentials of +0.26 and $+0.55 \mathrm{~V}$, respectively. The double peak pair indicated electron transfer via different copper centers (T2 and T1 for the lower and higher potential peaks, respectively) in T. versicolor laccase [28], although the peak potential is somewhat lower than the previously reported values $[28,29]$ perhaps because of the changed conformation of enzyme. Thus, the SAM modification of
np-Au educed the redox electron transfer at the T1 copper center of immobilized laccase.

The peak current for the laccase-immobilized np-Au electrode with SAM increased during repeated CV cycles. This may be perhaps due to the synergistic effect of electrochemical cleaning of $\mathrm{Au}$ electrode surface and orientation change during the CV cycles. However, laccase on the smooth $\mathrm{Au}$ surface (without nanoporous structure) exhibited a current decrease after 100 cycles, even when modified with the SAM (inset in Fig. 2b). Laccase could not be fully stabilized on the smooth Au surface because of the lack of nanoporous structure to geometrically confine the enzyme. Another reason for the decreased activity is that the SAM on the smooth $\mathrm{Au}$ surface had a weaker binding energy than that on nanostructured $\mathrm{Au}$ and was more readily desorbed during CV [30, 31]. The nanoporous structure and SAM were responsible for the electrochemical stability of the immobilized enzyme as $\mathrm{np}-\mathrm{Au}$ geometrically captured laccase which formed strong bonding with the SAM. Furthermore, SAM itself promotes the direct electron transfer between gold and laccase $[20,32,33]$. Such high stability of enzyme and SAM may synergistically promote electron transfer through the enzyme-SAM electrode system.

$\mathrm{CV}$ curves of GOx-immobilized np-Au electrodes with and without SAM-modification are shown in Fig. 3. No redox peak was observed in CV curves of GOx-immobilized np-Au without a SAM (Fig. 3a); thus, this electrode exhibited no electron transfer. However, SAM-modification of np-Au resulted in an obvious redox peak pair (midpoint potential of $+0.55 \mathrm{~V}$ ) in the $\mathrm{CV}$ curve (Fig. 3b). This was accompanied by anodic prepeaks which have been related to fast second-order reactions [34]. The 4-ATP SAM appeared to bridge the electronic gap (a) Without SAM

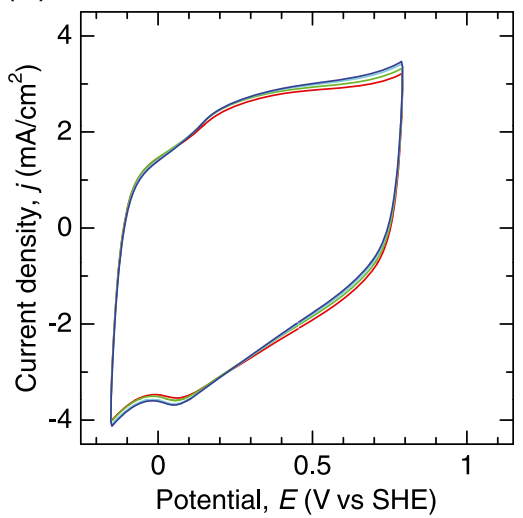

Fig. 2 Cyclic voltammetry curves for laccase-immobilized nanoporous $\mathrm{Au}$ (np-Au) working electrodes with (a) and without (b) a self-assembled monolayer $(S A M)$ of 4-aminothiophenol. Inset in $\mathbf{b}$ shows CV curve for laccase-immobilized smooth surface of Au with the SAM. Laccases (b) With SAM

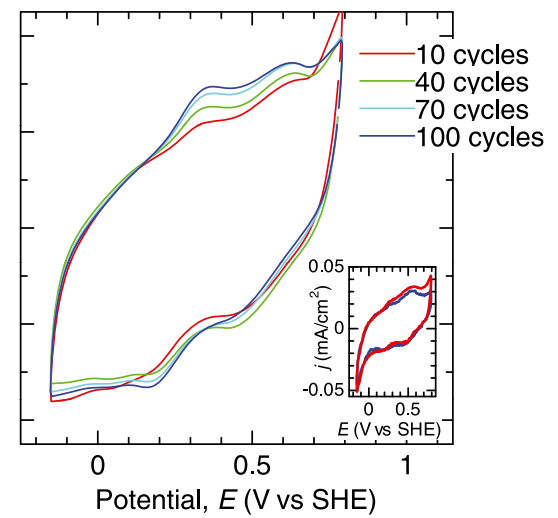

(T. versicolor with an activity of $21 \mathrm{U} / \mathrm{mg}$ ) were immobilized by soaking of $\mathrm{np}-\mathrm{Au}$ (both with and without SAM-modification) in $2 \mathrm{~mL}$ of $7 \mathrm{mg} / \mathrm{mL}$ laccase solutions diluted with $0.1 \mathrm{M}$ citrate $-0.2 \mathrm{M}$ phosphate buffer solution $(\mathrm{pH}=5.0)$ at $4^{\circ} \mathrm{C}$ for $24 \mathrm{~h}$ 
(a) Without SAM

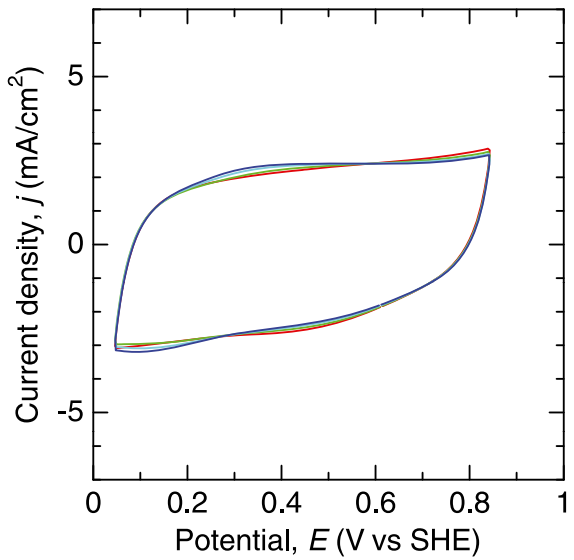

(b) With SAM

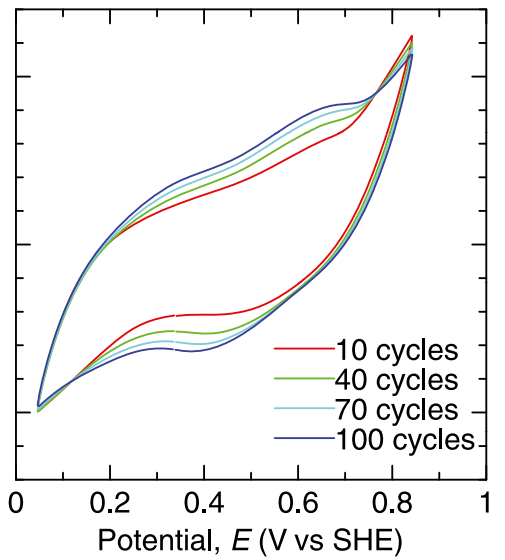

Fig. 3 Cyclic voltammetry curves for glucose oxidase (GOx)immobilized nanoporous $\mathrm{Au}(\mathrm{np}-\mathrm{Au})$ working electrodes with (a) and without (b) a self-assembled monolayer $(S A M)$ of 4-aminothiophenol. GOx (Aspergillus niger with an activity of $273 \mathrm{U} / \mathrm{mg}$ ) were immobilized

between the enzyme and electrode. It has been known that SAM with amine groups stabilizes $\mathrm{GOx}$ on $\mathrm{Au}$ electrode and enhances the electron transfer communication via covalent bonding [35]. Thus, the SAM on the np$\mathrm{Au}$ electrodes effectively activated and stabilized GOx as well as laccase. However, the detailed nature of the strong bonding between SAM and enzymes is currently unknown. Raman and/or infrared spectroscopic elucidation may help in the understanding of the bonding state.

\section{Electron transfer at defective surface}

The effective direct electron transfer between electrolyte and electrode observed for enzyme-immobilized $\mathrm{np}-\mathrm{Au}$ electrodes with SAM may have arisen from a defective surface structure $[30,36]$. To investigate the effect of surface structure on electron transfer, first-principles calculations with CASTEP code were conducted. Figure 4 shows calculated local density of states (DOS) of $\mathrm{Au}$ atoms on the (111) surface of (a) perfect (no defect), (b) honeycomb (with defect), and (c) adatom (with defect) models. It has been reported that sharp peaks and quasigaps in DOS around the Fermi level indicate strong directional bonding, whereas a broad DOS around the Fermi level indicates isotropic-like metallic bonding $[37,38]$. In the perfect model, sharp peaks were observed around the Fermi level, which indicated the origin of highly anisotropic electronic properties of the perfect $\mathrm{Au}$ (111) surface. Such localized DOS may have shortened the mean free path of surface electrons because of its constraint. The defective honeycomb and adatom models showed almost no quasi-gap around the Fermi level, which increased the mean free path of surface electrons. These properties by soaking of np-Au (both with and without SAM-modification) in $2 \mathrm{~mL}$ of $7 \mathrm{mg} / \mathrm{mL}$ GOx solutions diluted with $0.1 \mathrm{M}$ citrate- $0.2 \mathrm{M}$ phosphate buffer solution $(\mathrm{pH}=5.0)$ at $4^{\circ} \mathrm{C}$ for $24 \mathrm{~h}$

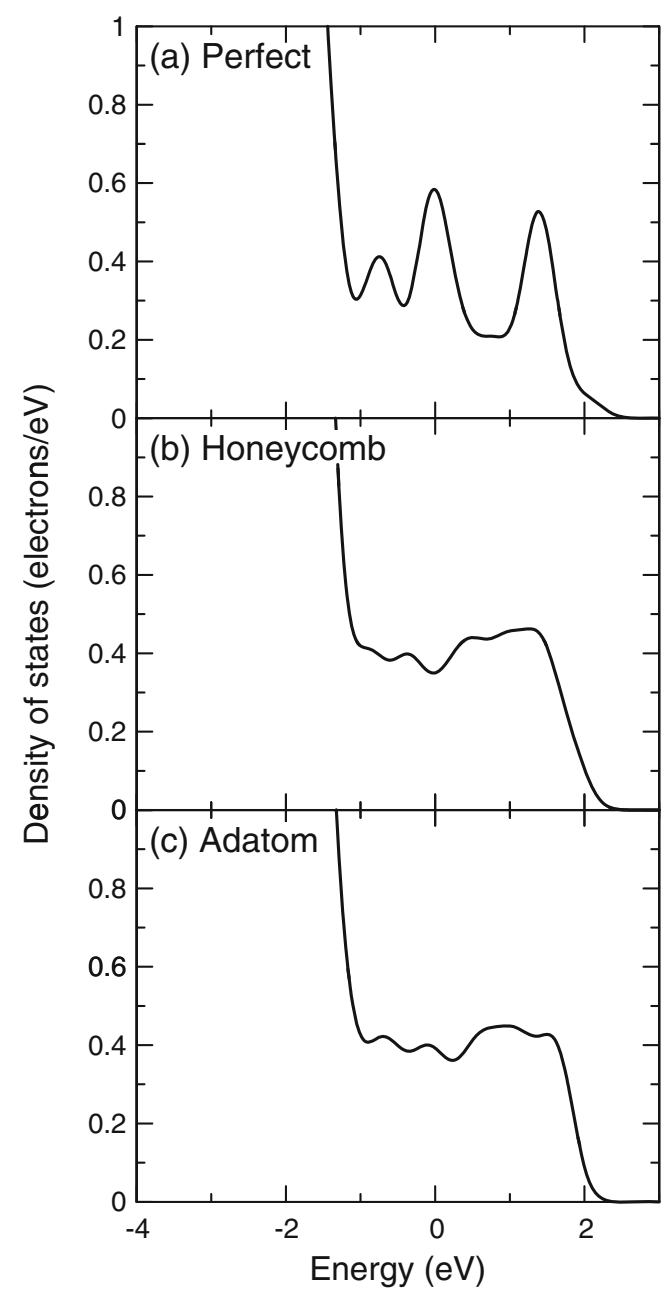

Fig. 4 Local density of states of (111) surface Au atom in a perfect, b honeycomb, and $\mathbf{c}$ adatom models calculated by first-principles calculations with CASTEP code. Fermi energy is set to 0 in the horizontal axes 
of defective surfaces may have facilitated the electron transfer between SAM and metal, and consequently rendered SAM-modified nanoporous metals favorable for enzymeimmobilized electrodes. In other words, the coupling of defective surface and SAM modification might effectively enhance the electron transfer.

Preliminary performance of biofuel cells

To utilize the improved activities of the enzymes immobilized on SAM-modified np-Au, a glucose $/ \mathrm{O}_{2}$ biofuel cell consisting of GOx- and laccase-immobilized np-Au electrodes with SAM was preliminarily fabricated [39, 40]. The operating principle of the fabricated biofuel cell is shown in Fig. 5a. At the GOx-immobilized np-Au anode, glucose was oxidized to gluconic acid. At the laccaseimmobilized np-Au cathode, $\mathrm{O}_{2}$ was reduced to water by the bioelectrocatalysis of stabilized laccase. The power density vs current density plot of the glucose $/ \mathrm{O}_{2}$ biofuel cell was measured by a source measure unit (GS200 by Yokogawa Meter \& Instruments Corp.) at $20^{\circ} \mathrm{C}$ in $250 \mathrm{~mL}$ of air-saturated buffer solution $(\mathrm{pH}=5.0)$ containing $100 \mathrm{mM}$ glucose. The distance between the anode and cathode was $12 \mathrm{~mm}$.

Figure $5 \mathrm{~b}$ shows the cell voltage and power density vs current density of the fabricated biofuel cell. The maximum power density delivered by the biofuel cell was $52 \mu \mathrm{W} / \mathrm{cm}^{2}$ at $0.21 \mathrm{~V}$. The results were reproducible in two tests, although the full reproducibility should be clarified for further investigation.

Many recent studies have been conducted on glucose $/ \mathrm{O}_{2}$ system biofuel cells. For example, power densities of $64 \mu \mathrm{W} / \mathrm{cm}^{2}$ at $23^{\circ} \mathrm{C}$ have been obtained using carbon fiber $(2 \mathrm{~cm} \times 7 \mu \mathrm{m})$ electrodes [8]. A high power production of
$442 \mu \mathrm{W} / \mathrm{cm}^{2}$ was delivered by DNA-wrapped single-wall carbon nanotubes at room temperature [41]. Recent studies incorporating carbon nanotube electrodes shows higher maximum output of $740 \mu \mathrm{W} / \mathrm{cm}^{2}$ [42] and $1,300 \mu \mathrm{W} / \mathrm{cm}^{2}$ [40]. The maximum output of the present glucose $/ \mathrm{O}_{2}$ biofuel cell $\left(52 \mu \mathrm{W} / \mathrm{cm}^{2}\right)$ is lower than those of other biofuel cells composed of GOx and laccase electrodes. However, there remains room for improvement. For example, the pore size should be optimized to immobilize maximum enzyme and to enhance the accessibility of cofactors and substrate. Altering the SAM to be more favorable for the respective enzymes is another possible method. Fuel cell configuration including electrode distance should be refined for the performance improvement. And also, for practical application, time variation and reproducibility of the cell performance are to be examined in more detail.

\section{Conclusions}

To conclude, the electrochemical properties of enzymeimmobilized np-Au were examined. SAM-modified np-Au had an increased stabilizing effect on enzymes compared with the smooth Au surface. The SAM was stabilized at the defective np-Au surface. Defective surfaces significantly contributed to the improved electron transfer between electrode and enzyme through SAM, resulting in increased operating current. These findings suggest that np-Au is a promising material for biofuel cells. Combined with biocompatibility and stability of np-Au, SAMmodification renders np-Au material favorable for the preparation of biofuel cells and enhancing their performance. Further research is necessary to improve enzyme stability, electronic conductivity, and consequent power production.
Fig. 5 a Schematic illustration of fabricated biofuel cell comprising glucose oxidase-immobilized nanoporous $\mathrm{Au}(\mathrm{np}-\mathrm{Au})$ anode and laccase-immobilized np-Au cathode. b Cell voltage and power density vs current density plots generated from the fabricated biofuel cell at $20^{\circ} \mathrm{C}$

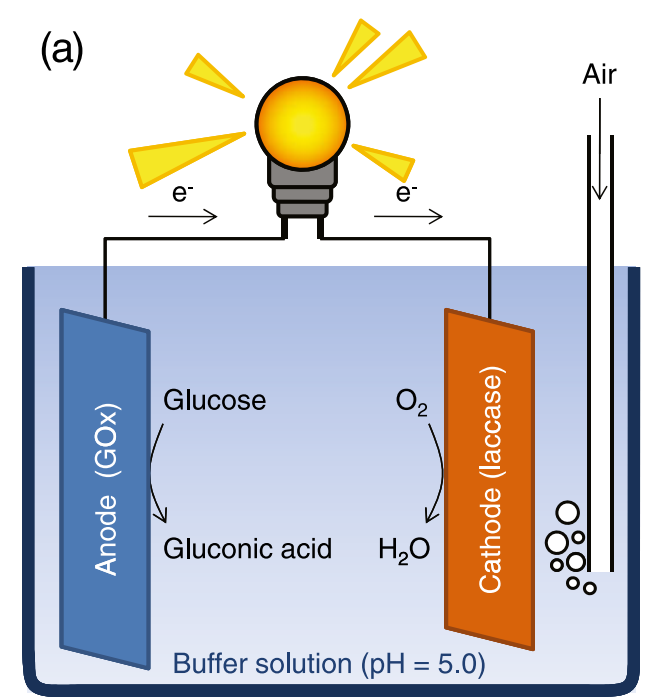

(b)

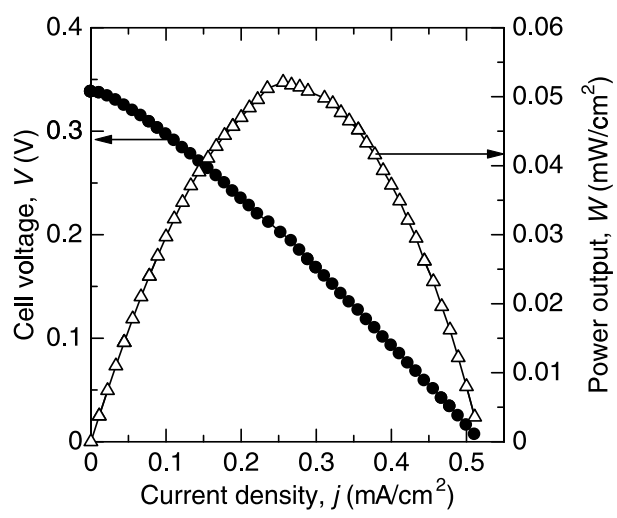


Acknowledgement This study was supported by JSPS KAKENHI (22656155).

Open Access This article is distributed under the terms of the Creative Commons Attribution License which permits any use, distribution and reproduction in any medium, provided the original author(s) and source are credited.

\section{References}

1. Bullen RA, Arnot TC, Lakeman JB, Walch FC (2006) Biofuel cells and their development. Biosens Bioelectron 21:2015-2045

2. Yuhashi N, Tomiyama M, Okuda J, Igarashi S, Ikebukuro K, Sode K (2005) Development of a novel glucose enzyme fuel cell system employing protein engineered PQQ glucose dehydrogenase. Biosens Bioelectron 20:2145-2150

3. Pizzariello A, Stred'ansky M, Miertuš S (2002) A glucose/ hydrogen peroxide biofuel cell that uses oxidase and peroxidase as catalysts by composite bulk-modified bioelectrodes based on a solid binding matrix. Bioelectrochemistry 56:99105

4. Katz E, Bückmann AF, Willner I (2001) Self-powered enzymebased biosensors. J Am Chem Soc 123:10752-10753

5. Kendall K (2002) Fuel cell technology - a sweeter fuel. Nat Mater $1: 211-212$

6. Service RF (2002) Fuel cells: shrinking fuel cells promise power in your pocket. Science 296:1222-1224

7. Jeon SW, Lee JY, Lee JH, Kang SW, Park CH, Kim SW (2008) Optimization of cell conditions for enzymatic fuel cell using statistical analysis. J Ind Eng Chem 14:338-343

8. Chen T, Barton SC, Binyamin G, Gao Z, Zhang Y, Kim HH, Heller A (2001) A miniature biofuel cell. J Am Chem Soc 123:8630 8631

9. Barton SC, Gallaway J, Atanassov P (2004) Enzymatic biofuel cells for implantable and microscale devices. Chem Rev 104:4867-4886

10. Akers NL, Moore CM, Minteer SD (2005) Development of alcohol $/ \mathrm{O}_{2}$ biofuel cells using salt-extracted tetrabutylammonium bromide/Nafion membranes to immobilize dehydrogenase enzymes. Electrochim Acta 50:2521-2525

11. Heller A (2004) Miniature biofuel cells. Phys Chem Chem Phys 6:209-216

12. Tsujimura S, Fujita M, Tatsumi H, Kano K, Ikeda T (2001) Bioelectrocatalysis-based dihydrogen/dioxygen fuel cell operating at physiological pH. Phys Chem Chem Phys 3:1331-1335

13. Liu Y, Wang M, Zhao F, Liu B, Dong S (2005) A low-cost biofuel cell with $\mathrm{pH}$-dependent power output based on porous carbon as matrix. Chem Eur J 11:4970-4974

14. Qiu H, Xu C, Huang X, Ding Y, Qu Y, Gao P (2008) Adsorption of laccase on the surface of nanoporous gold and the direct electron transfer between them. J Phys Chem C 112:14781-14785

15. Qiu H, Xu C, Huang X, Ding Y, Qu Y, Gao P (2009) Immobilization of laccase on nanoporous gold: comparative studies on the immobilization strategies and the particle size effects. J Phys Chem C 113:2521-2525

16. Shulga OV, Jefferson K, Khan AR, D'Souza VT, Liu J, Demchenko AV, Stine KJ (2007) Preparation and characterization of porous gold and its application as a platform for immobilization of acetylcholine esterase. Chem Mater 19:3902-3911

17. Xiao Y, Patolsky F, Katz E, Hainfeld JF, Willner I (2003) "Plugging into enzymes": nanowiring of redox enzymes by a gold nanoparticle. Science 299:1877-1881
18. Hudson S, Cooney J, Magner E (2008) Proteins in mesoporous silicates. Angew Chem Int Ed 47:8582-8594

19. Rekuć A, Bryjak J, Szymańska K, Jarzębski AB (2009) Laccase immobilization on mesostructured cellular foams affords preparations with ultra high activity. Process Biochem 44:191-198

20. Gupta G, Rajendran V, Atanassov P (2004) Bioelectrocatalysis of oxygen reduction reaction by laccase on gold electrodes. Electroanalysis 16:1182-1185

21. Payne MC, Teter MP, Allan DC, Arias TA, Joannopoulos JD (1992) Iterative minimization techniques for ab initio total-energy calculations - molecular-dynamics and conjugate gradients. Rev Mod Phys 64:1045-1097

22. Hohenberg P, Kohn W (1964) Inhomogeneous electron gas. Phys Rev 136:B864-B871

23. Kohn W, Sham LJ (1965) Self-consistent equations including exchange and correlation effects. Phys Rev 140:A1133-A1138

24. Perdew JP, Burke K, Ernzerhof M (1996) Generalized gradient approximation made simple. Phys Rev Lett 77:3865-3868

25. Vanderbilt D (1990) Soft self-consistent pseudopotentials in a generalized eigenvalue formalism. Phys Rev B 41:7892-7895

26. Molina LM, Hammer B (2002) Theoretical study of thiol-induced reconstructions on the $\mathrm{Au}(111)$ surface. Chem Phys Lett 360:264 271

27. Carro P, Salvarezza R, Torres D, Illas F (2008) On the thermodynamic stability of $(\sqrt{3} \times \sqrt{3})$ R $30^{\circ}$ methanethiolate lattice on reconstructed $\mathrm{Au}$ (111) surface models. J Phys Chem C 112:19121-19124

28. Frasconi M, Boer H, Koivula A, Mazzei F (2010) Electrochemical evaluation of electron transfer kinetics of high and low redox potential laccases on gold electrode surface. Electrochim Acta $56: 817-827$

29. Reinhammer BRM (1972) Oxidation-reduction potentials of the electron acceptors in laccases and stellacyanin. Biochim Biophys Acta 275:245-259

30. Cortés E, Rubert AA, Benitez G, Carro P, Vela ME, Salvarezza RC (2009) Enhanced stability of thiolate self-assembled monolayers (SAMs) on nanostructured gold substrates. Langmuir 25:5661-5666

31. Hakamada M, Takahashi M, Furukawa T, Tajima K, Yoshimura K, Chino Y, Mabuchi M (2011) Electrochemical stability of self-assembled monolayers on nanoporous Au. Phys Chem Chem Phys 13:12277-12284

32. Pita M, Shleev S, Ruzgas T, Fernández VM, Yaropolov AI, Gorton L (2006) Direct heterogeneous electron transfer reactions of fungal laccases at bare and thiol-modified gold electrodes. Electrochem Commun 8:747-753

33. Shleev S, Pita M, Yaropolov AI, Ruzgas T, Gorton L (2006) Direct heterogeneous electron transfer reactions of Trametes hirsuta laccase at bare and thiol-modified gold electrodes. Electroanalysis 18:1901-1908

34. Yokoyama K, Kayanuma Y (1998) Cyclic voltammetric simulation for electrochemically mediated enzyme reaction and determination of enzyme kinetic constants. Anal Chem 70:33683376

35. Willner I, Riklin A, Shoham B, Rivenzon D, Katz E (1993) Development of novel biosensor enzyme electrodes-glucoseoxidase multilayer arrays immobilized onto self-assembled monolayers electrodes. Adv Mater 5:912-915

36. Hakamada M, Nakano H, Furukawa T, Takahashi M, Mabuchi M (2010) Hydrogen storage properties of nanoporous palladium fabricated by dealloying. J Phys Chem C 114:868-873

37. Liu YL, Liu LM, Wang SQ, Ye HQ (2007) First-principles study of shear deformation in $\mathrm{TiAl}$ and $\mathrm{Ti}_{3} \mathrm{Al}$. Intermetallics $15: 428-435$

38. Woodward C, MacLaren JM, Rao S (1992) Electronic-structure of planar faults in TiAl. J Mater Res 7:1735-1750 
39. Brunel L, Denele J, Servat K, Kokoh KB, Jolivalt C, Innocent C, Cretin M, Rolland M, Tingry S (2007) Oxygen transport through laccase biocathodes for a membrane-less glucose $/ \mathrm{O}_{2}$ biofuel cell. Electrochem Commun 9:331-336

40. Zebda A, Gondran C, Le Goff A, Holzinger M, Cinquin P, Cosnier S (2011) Mediatorless high-power glucose biofuel cells based on compressed carbon nanotube-enzyme electrodes. Nat Commun 2:370
41. Lee JY, Shin HY, Kang SW, Park C, Kim SW (2010) Use of bioelectrode containing DNA-wrapped single-walled carbon nanotubes for enzyme-based biofuel cell. J Power Sourc 195:750-755

42. Gao F, Viry L, Maugey M, Poulin P, Mano N (2010) Engineering hybrid nanotube wires for high-power biofuel cells. Nat Commun $1: 2$ 